\title{
Correspondence
}

\section{Ultrasound-guided caudal approach to combined spinal-epidural for major abdominal surgery in high risk premature newborns}

To the Editor,

This letter is intended to present an innovative approach to regional anesthesia (RA) in small ex-premature babies.

Preterm infants often have a history of apnea of prematurity, bronchopulmonary dysplasia and chronic lung disease. Spinal anesthesia is a well-accepted anesthetic technique for ex-premature infants undergoing lower abdominal surgery. Its major advantages over general anesthesia are the minimization of postoperative apnea risk and the need for ventilatory support [1].

The practice of general anesthesia (GA) might have a negative impact regarding those issues.

Ultrasound equipment has enabled the development of new anesthetic approaches to neuraxial anesthesia.

After obtaining written parental consent to publish, we report the case of an ex-premature infant submitted to supraumbilical abdominal surgery under ultrasound-guided trans-caudal, combined spinal-epidural anesthesia.

\section{Case report}

A 3-month-old female infant ( 24 weeks and $2 \mathrm{~d}$ preterm), weighing $2030 \mathrm{~g}$, with history of pulmonary dysplasia, chronic renal disease, necrotizing enterocolitis, previously submitted to major abdominal surgery under GA, was presented for ileal and colonic reconstruction surgery.

Under ASA standard monitorization, sedation was initiated with ketamine $(0.5 \mathrm{mg} / \mathrm{kg})$ and propofol $(1 \mathrm{mg} / \mathrm{kg})$. Oxygen was applied by facial mask with $50 \% \mathrm{O}_{2}$. The infant was placed in the left lateral position and a high frequency $12 \mathrm{MHz}$ linear probe was used to visualize the epidural space in a parasagittal plane until the tip of the dural sac was seen. Under direct visualization, using a BBraun ${ }^{\circledR} 50 \mathrm{~mm} 20 \mathrm{G}$ caudal needle, the caudal epidural space was reached. Through the caudal needle, a BBraun $^{\circledR} 90 \mathrm{~mm}$ 27G Quinck spinal needle was then inserted until the dural sac was pierced. Correct placement of the needle was confirmed by the free flux of cerebrospinal fluid and $0.6 \mathrm{mg} / \mathrm{kg}$ of bupivacaine $0.5 \%$ was administered. An epidural catheter

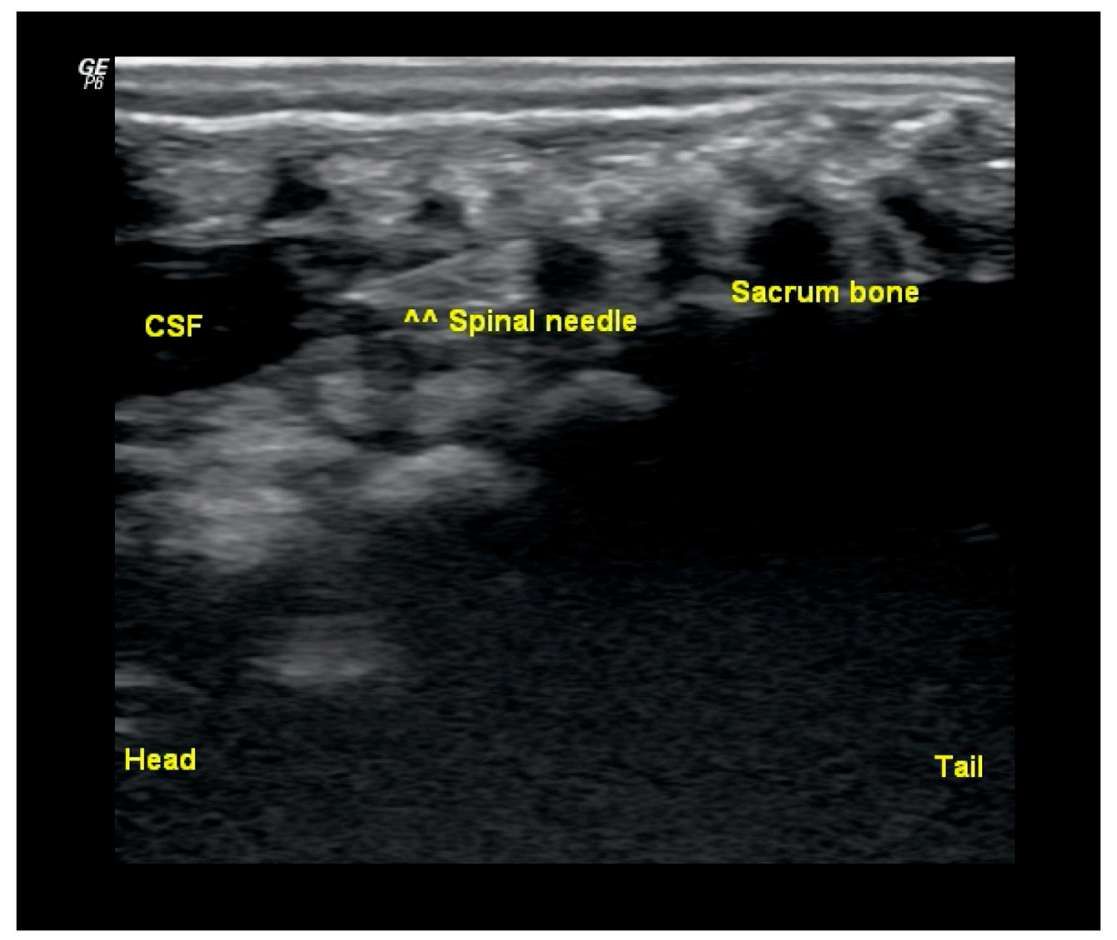

Fig. 1. Spinal needle piercing the dural sac. 
was then threaded through the caudal needle, in the epidural space, under ultrasound guidance, reaching L1 level (Fig. 1).

During surgery sedation was maintained with a propofol infusion at $5 \mathrm{mg} / \mathrm{kg} / \mathrm{h}$. Two epidural top-ups were administered ( 1 and $2 \mathrm{~h}$ after spinal block with $0.5 \mathrm{ml} / \mathrm{kg}$ of ropivacaine $0.2 \%$ and $0.1 \%$, respectively).

The infant was kept in spontaneous ventilation through the entire procedure, lasting for $3 \mathrm{~h}$. Towards the end of surgery, an epidural infusion of ropivacaine $0,05 \%$ was started at $0,2 \mathrm{mg} / \mathrm{kg} / \mathrm{h}$.

She was re-admitted in neonatal intensive care unit, hemodynamically stable, spontaneously breathing and normocapnic.

With this successful case, we consider that combined spinal-epidural anesthesia might be considered a viable alternative to general anesthesia for abdominal procedures in ex-premature infant, as it adds positive consistency to previous reports of successful spinal-epidural ultrasound-guided caudal blocks for abdominal surgery [2].

Given our patient's severe comorbidities, we considered RA with light sedation to be a beneficial anesthetic approach.

Recent investigations report that epidural analgesia is better than conventional opioid therapy for abdominal procedures, as prematures and newborns are particularly sensitive to the respiratory depressant effects of systemic opioids [3]. Another recent publication states that RA is advantageous for lower abdominal procedures in ex-premature infants, by reducing the incidence of apnea in the post-operatory period and avoiding airway manipulation and mechanical ventilation in patients with history of respiratory problems [4].

Ultrasound guided spinal-epidural technique by the described trans- caudal approach offers the advantage of inserting the epidural catheter with a single skin-puncture in a safety matter. This allows for maintenance of adequate anesthesia during procedures lasting more than $1 \mathrm{~h}$ and optimal postoperative analgesia.

In summary, we consider this original approach to be a viable alternative to GA for abdominal procedures in ex-premature infants. However, there are still few cases described in literature, and it is our belief that prospective studies are necessary to fully validate the technique as the anesthetic plan of choice for this particular population.

\section{References}

[1] Marhofer P, Keplinger M, Klug W, Metzelder ML. Awake caudals and epidurals should be used more frequently in neonates and infants. Paediatr Anaesth 2015;25:93-9.

[2] Trindade H, Silva R, Rocha T. Combined spinal-epidural ultrasound-guided caudal block in an infant. Anaesth Cases 2016. (e2016-0013). https://www. anaesthesiacases.org/case-reports/2016-0013.

[3] Bosenberg A. Benefits of regional anesthesia in children. Paediatr Anaesth 2012;22:10-8.

[4] Gerber AC. Spinal and caudal anaesthesia in ex-premature babies. Baillieres Best Pract Res Clin Anaesthesiol 2000;14(4):673-85.

$$
\begin{array}{r}
\text { Joana Barros-Silva }{ }^{\mathrm{a}, *} \text {, Joana Jones }{ }^{\mathrm{b}} \text {, Hugo Trindade }{ }^{\mathrm{c}} \\
{ }^{\mathrm{a}} \text { Baixo Vouga Hospitalar Center, Aveiro, Portugal } \\
{ }_{\mathrm{b}}^{\mathrm{b}} \text { Luz Hospital, Lisbon, Portugal } \\
{ }^{\mathrm{c}} \text { Central Lisbon Hospitalar Center, Dona Estefânia Hospital, Lisbon, } \\
\text { Portugal } \\
\text { E-mail address: joanarbsilva@gmail.com (J. Barros-Silva). }
\end{array}
$$

